\title{
EGFR Inhibitor Enhances Cisplatin Sensitivity of Oral Squamous Cell Carcinoma Cell Lines
}

\author{
Yukihiro Hiraishi • Takeshi Wada • Ken Nakatani • \\ Itaru Tojyo • Takashi Matsumoto • Norifumi Kiga • \\ Kenji Negoro $\cdot$ Shigeyuki Fujita
}

Received: 25 January 2008 / Accepted: 20 February 2008 /Published online: 7 March 2008

(C) The Author(s) 2008

\begin{abstract}
Epidermal growth factor receptor (EGFR) is involved in multiple aspects of cancer cell biology. EGFR has already been identified as an important target for cancer therapy, with various kinds of EGFR inhibitors currently used in treatment of several human cancers. Recently, EGFR and its downstream signaling pathways were identified as being associated with cisplatin sensitivity. In addition, EGFR inhibitors have shown significant promise for patients who failed cisplatin-based therapy. In this study, we investigated whether treatment with an EGFR inhibitor improves cisplatin sensitivity in oral squamous cell carcinoma (OSCC) cell lines. The effects of a combination of AG1478, a specific EGFR tyrosine kinase inhibitor, with cisplatin were evaluated in cultured OSCC cell lines and cisplatin-resistant sublines. Higher expression of EGFR and p-EGFR was found in the two cisplatin-resistant cell lines compared with the corresponding parental cell lines. In addition, augmented inhibition of OSCC cell growth by the combination of AG1478 with cisplatin was found in both cell lines. These results suggest that the combination of an EGFR inhibitor and cisplatin may be useful as a rational strategy for the treatment of patients with oral cancer with acquired cisplatin resistance.
\end{abstract}

Keywords Epidermal growth factor receptor (EGFR) EGFR inhibitor - Oral squamous cell carcinoma (OSCC) . Cisplatin-resistant OSCC cell line .

Cisplatin sensitivity and resistance

Y. Hiraishi $(\bowtie) \cdot$ T. Wada $\cdot$ K. Nakatani $\cdot$ I. Tojyo $•$

T. Matsumoto $\cdot$ N. Kiga $\cdot$ K. Negoro $\cdot$ S. Fujita

Department of Oral and Maxillofacial Surgery,

Wakayama Medical University,

811-1 Kimiidera,

641-8509 Wakayama, Japan

e-mail: hiraishi@wakayama-med.ac.jp

\author{
Abbreviations \\ (CDDP) cisplatin \\ (DMEM) Dulbecco's modified Eagle's medium \\ (EGFR) epidermal growth factor receptor \\ (FBS) fetal bovine serum \\ (PBS) phosphate buffered saline \\ (p-EGFR) phosphorylated EGFR \\ (SDS) sodium dodecyl sulfate
}

\section{Introduction}

Epidermal growth factor receptor (EGFR) is expressed at high levels in a variety of solid tumors including oral cancers $[1,2]$. EGFR and its downstream signaling pathways are involved in multiple aspects of cancer cell biology, including tumor cell proliferation, inhibition of apoptosis, invasion, metastasis, and angiogenesis [1-4]. EGFR has already been identified as an important target for cancer therapy, and various kinds of EGFR inhibitors are currently used in the treatment of several human cancers [5-10].

Cisplatin-based combination chemotherapy displays significant anti-tumor activity against solid tumors of oral squamous cell carcinoma (OSCC). However, the effectiveness of cisplatin in the treatment of recurrent/metastatic tumors is limited because of acquired or intrinsic resistance. EGFR and its signaling pathways are involved in the mechanism of cisplatin resistance. Cells that are resistant to cisplatin have an altered response to the EGF ligand and enhanced activation of the protein kinase [11]. In addition, several studies have suggested that enhanced expression of EGFR may be associated with cisplatin resistance in a variety of solid tumors including oral cancers [12, 13]. Increased EGFR expression may be a survival response by some tumors exposed to chemotherapeutic agents [14]. 
Increased availability of EGFR inhibitors in cisplatinresistant cells has also been reported previously [13]. EGFR inhibitors have shown significant activity in cases failing cisplatin-based therapy $[15,16]$. Therefore, EGFR blockade may be a useful therapeutic tool in the treatment of patients with acquired cisplatin resistance.

In this study, we established a cisplatin-resistant cell line from an OCSS-derived cell line and investigated the differential EGFR and phosphorylated EGFR (p-EGFR) expression between OSCC cell lines and the cisplatinresistant sublines. In addition, we examined the effect of combination therapy with an EGFR inhibitor and cisplatin on the growth of OSCC cells.

\section{Materials and Methods}

\section{Cell Lines}

Two human OSCC cell lines have been established at Wakayama Medical University, Wakayama, Japan. The H-1 line was derived from a biopsy specimen of moderately differentiated OSCC in the lower gingiva. The Sa-3 line was derived from a biopsy specimen of well-differentiated OSCC in the upper gingiva. Both cell lines were cultured in Dulbecco's modified Eagle's medium (DMEM; Nissui, Tokyo, Japan) supplemented with $10 \%$ fetal bovine serum (FBS; Equitech-Bio, Kerrville, TX, USA), 100 units/ml penicillin, and $100 \mu \mathrm{g} / \mathrm{ml}$ streptomycin (Gibco BRL, Grand Island, NY, USA) in a highly humidified atmosphere of 5\% $\mathrm{CO}_{2}$ at $37^{\circ} \mathrm{C}$.

In accordance with previously described methods [17, 18], the cisplatin (CDDP)-resistant sublines H-1/CDDP and Sa-3/CDDP were established by repeated subculture in the presence of increasing concentrations of cisplatin (Nippon Kayaku Corporation, Tokyo, Japan), from $0.1 \mu \mathrm{g} / \mathrm{ml}$ until cells became fully resistant to cisplatin and could grow exponentially; in each case the final cisplatin concentration was $0.5 \mu \mathrm{g} / \mathrm{ml}$. The drug-resistant cell lines were passed in drug-free medium, and there was no loss of resistance during the two-month testing period.

\section{Cell Growth Analysis with MTT Assay}

Cells were seeded in 96-well plates at 2000 cells per well in DMEM containing 10\% FBS. After $24 \mathrm{~h}$, cells were exposed to one of nine concentrations $(0.05,0.1,0.25$, $0.5,1,1.25,2.5,5$ and $10 \mu \mathrm{g} / \mathrm{ml})$ of cisplatin or five concentrations $(1,5,10,20$ and $30 \mu \mathrm{M})$ of AG1478 (Calbiochem San Diego CA, USA). After cells were incubated with cisplatin or AG1478 for $24 \mathrm{~h}$, medium was changed to drug-free DMEM and cells were incubated for an additional $72 \mathrm{~h}$. Thereafter, the number of cells per well was quantified with a MTT cell growth assay kit (Funakoshi, Tokyo, Japan) according to the manufacturer's instructions. Briefly, after $10 \mu$ MTT solution was added to each well, the well was incubated for $4 \mathrm{~h}$ and scanned at $550-630 \mathrm{~nm}$ by a MTP-300 microplate reader (Corona, Tokyo, Japan). Six wells were used for each drug concentration, and the experiment was repeated three times. The $50 \%$ inhibitory concentration (IC50) was calculated from the survival curve. In another experiment, to test whether the combination of cisplatin and AG1478 would achieve higher growth inhibition than the single agent at a concentration lower than the IC50, fixed concentrations of each drug were then tested in combination treatment of OSCC cell lines. All cells were exposed to AG1478 for $1 \mathrm{~h}$ before cisplatin. The statistical significance of differences was analyzed by applying Mann-Whitney $U$-test. The level of significance was set at $p<0.05$.

\section{Western Blot Analysis}

Subconfluent cells were scraped from culture dishes, washed twice with phosphate buffered saline (PBS), and suspended in $700 \mu \mathrm{l}$ Western blot lysis buffer containing $62.5 \mathrm{mM}$ Tris$\mathrm{HCl}$ (ph 6.8), 25\% glycerol, and 2\% sodium dodecyl sulfate (SDS). Samples were centrifuged at 15,000 rpm for $20 \mathrm{~min}$ at $4^{\circ} \mathrm{C}$, after which supernatants were collected. After heating at $95^{\circ} \mathrm{C}$ for $5 \mathrm{~min}$, equal amounts of proteins were separated with the use of $10 \%$ SDS-PAGE. After electrophoresis, proteins were transferred to a PVDF membrane in Trisglycine buffer containing 20\% methanol. The membrane was blocked with $3 \%$ skim milk containing $0.01 \%$ polyoxyethlene sorbitan monolaurate for $60 \mathrm{~min}$, and incubated overnight with the corresponding primary antibodies a 1:750 dilution of anti-rabbit polyclonal EGFR antibody [Santa Cruz Biotechnology, Santa Cruz, CA, USA], and a 1:750 dilution of anti-goat polyclonal p-EGFR (Tyr 1173) antibody [Santa Cruz Biotechnology] $\}$ at $4^{\circ} \mathrm{C}$. The membrane was washed three times for 5 min each with PBS containing $0.05 \%$ polyoxyethlene sorbitan monolaurate and horseradish peroxidase-conjugated anti-rabbit or anti-goat antibody for $1 \mathrm{~h}$ at room temperature, respectively. Protein signals were visualized by enhanced chemiluminescence using ECL Western blotting detection reagents (Amersham, Arlington Heights, IL, USA) for $1 \mathrm{~min}$ and exposed to Kodak Biomax XAR film.

\section{Results}

\section{Single Agent Effects}

The sensitivities of all cell lines to various concentrations of cisplatin and AG1478 were determined by MTT assay and 

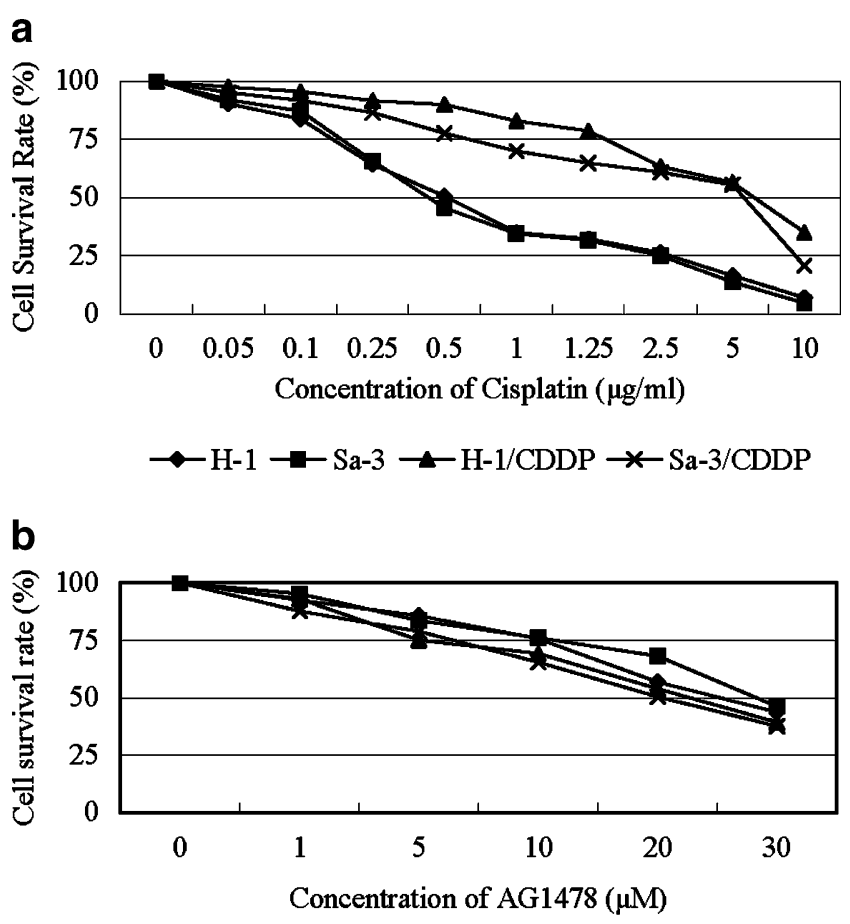

$\longrightarrow \mathrm{H}-1 \rightarrow \mathrm{Sa}-3 \rightarrow \mathrm{H}-1 / \mathrm{CDDP} \rightarrow \mathrm{Sa}-3 / \mathrm{CDDP}$

Fig. 1 Inhibitory effects of cisplatin and AG1478 on growth of OSCC cell lines. The four lines, H-1, H-1/CDDP, Sa-3, and Sa-3/CDDP, were treated with cisplatin $(0.05-10 \mu \mathrm{g} / \mathrm{ml}$; a) or AG1478 $(1-30 \mu \mathrm{M}$; b) for $24 \mathrm{~h}$ as described in the Materials and methods section. Cell viability was measured by MTT assay and is expressed as a percentage relative to control cells. The results showed that cisplatin and AG1478 inhibited OSCC cell growth in a dose-dependent manner

plotted on a survival curve (Fig. 1). The IC50 values of cisplatin and AG1478 are shown in Table 1. The IC50 values of the H-1/CDDP and Sa-3/CDDP lines to cisplatin were about 10 -fold greater than the values for the parental H-1 and Sa-3 lines. Resistance of all cell lines to AG1478 was similar, but the IC50 values for parental cell lines tended to be slightly higher.

\section{Combination Effects}

All cell lines were treated with AG1478 $(10 \mu \mathrm{M})$ for 1 hour before cisplatin $(0.25 \mu \mathrm{g} / \mathrm{ml})$ for $24 \mathrm{~h}$. The combination of AG1478 with cisplatin inhibited cell growth $>60 \%$ in

Table 1 Cisplatin and AG1478 sensitivity of OSCC cell lines

\begin{tabular}{|c|c|c|}
\hline Cell line & $\begin{array}{l}\text { IC50 } \\
\text { Cisplatin }(\mu \mathrm{g} / \mathrm{ml})\end{array}$ & $\begin{array}{l}\text { IC50 } \\
\text { AG1478 }(\mu \mathrm{M})\end{array}$ \\
\hline $\mathrm{H}-1$ & 0.49 & 25.3 \\
\hline $\mathrm{Sa}-3$ & 0.43 & 28.5 \\
\hline H-1/CDDP & 6.5 & 23.3 \\
\hline Sa-3/CDDP & 5.9 & 21.2 \\
\hline
\end{tabular}

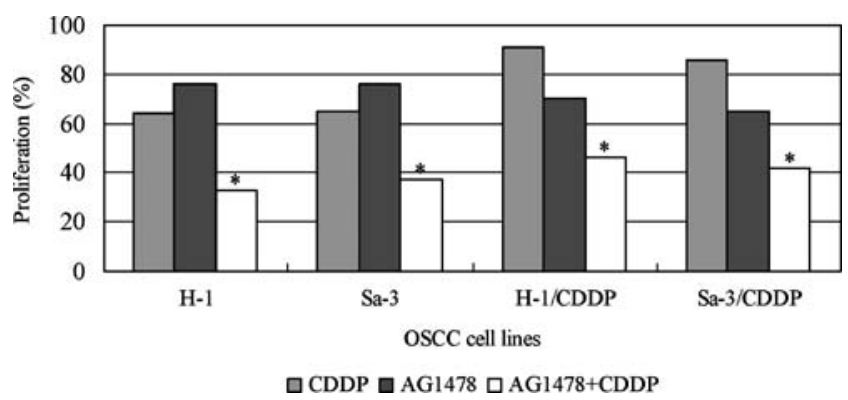

Fig. 2 Effect of a combination of AG1478 with cisplatin on growth of OSCC cell lines. The four lines, H-1, H-1/CDDP, Sa-3, and Sa-3/ CDDP, were treated with AG1478 $(10 \mu \mathrm{M})$ for $1 \mathrm{~h}$ before addition of cisplatin $(0.25 \mu \mathrm{g} / \mathrm{ml})$ for $24 \mathrm{~h}$. Cell viability was measured by MTT assay and is expressed as a percentage relative to control cells. In both cell lines, we showed augmented effects of inhibition and showed large-effect augmentation in cisplatin-resistant cell lines. ${ }^{*} p<0.05$, compared with cisplatin-treated cells

parental cell lines $>50 \%$ in cisplatin-resistant cell lines (Fig. 2). In both cell lines, we showed augmented effects of inhibition and showed a large effect of augmentation in cisplatin-resistant cell lines.

\section{Expression of EGFR and p-EGFR}

To investigate the molecular basis for the increased sensitivity of chemoresistant tumors to cisplatin, we used Western blot analysis to determine the level of EGFR and p-EGFR expression in parental and cisplatin-resistant cell lines. Higher EGFR and p-EGFR expression was found in cisplatin-resistant cell lines compared with the corresponding parental cell lines (Fig. 3).

\section{Discussion}

Our studies suggest that changes in the expression of EGFR play an important role in regulating the drug-resistant

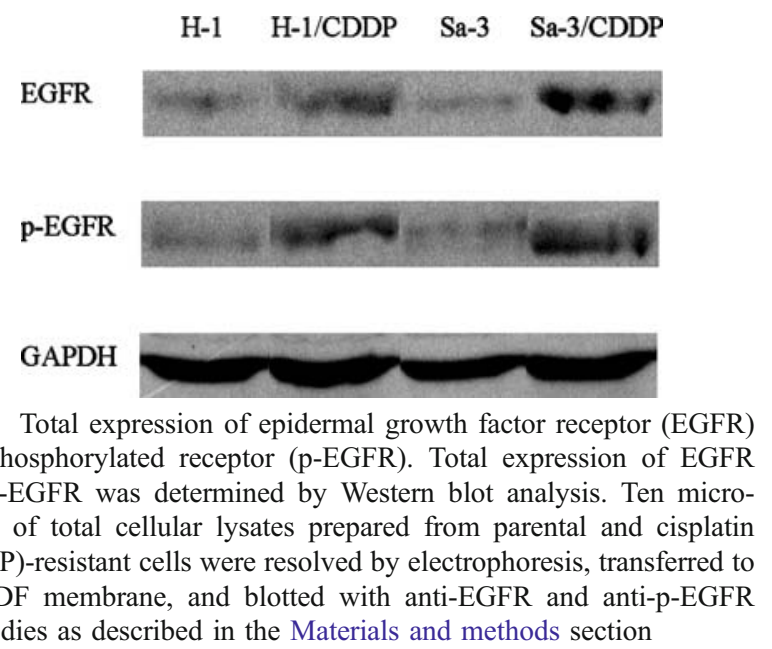


phenotype of cells in response to cisplatin. Cisplatin is widely used for chemotherapy of many malignancies, especially of oral squamous cell carcinoma (OSCC). However, the effectiveness of cisplatin in the treatment of recurrent/metastatic tumors is limited because of acquired or intrinsic resistance. Increased EGFR expression may be a survival response by some tumors exposed to chemotherapeutic agents [14]. In our study, higher EGFR expression was found in two cisplatin-resistant cell lines compared with the corresponding parental cell lines (Fig. 3).

EGF receptors initiate cytoplasmic signaling through autophosphorylation of their intracellular domains [19]. Phosphorylated EGFR (p-EGFR) cytoplasmic tyrosine residues initiate the activated protein kinase pathway [20]. This mitogen-activated protein kinase (MAPK) pathway is involved in the mechanism of cisplatin resistance [21-23]. Activation of JNK and p38 by cisplatin has been shown to promote apoptotic cell death $[22,23]$. In addition, activation of the ERK pathway by cisplatin was reported to promote induction of cell death [21]. In our study, higher pEGFR expression was found in two cisplatin-resistant cell lines compared with the corresponding parental cell lines. These findings offer further evidence that activation of EGFR downstream signaling pathways is involved in cisplatin sensitivity.

The effect of combining EGFR inhibitors with cytotoxic agents has been studied in various types of cancer [16, 24]. The quinazoline derivative AG1478 is a specific reversible inhibitor of EGFR. The cancer cell growth depression effect of AG1478 has been reported in various carcinomas [2426]. In our study, the combination of AG1478 and cisplatin showed augmented effects of inhibition in both cell lines and showed large-effect augmentation in cisplatin-resistant cell lines. These results suggest that acquired resistance to cisplatin is associated with enhanced sensitivity to an EGFR tyrosine kinase inhibitor, which correlates with increased EGFR and p-EGFR expression.

Augmented effects of inhibition of OSCC cell growth through the combination of AG1478 and cisplatin provide a potential and novel strategy for patients with oral cancer with acquired cisplatin resistance. In addition, it would be very advantageous if an equal chemotherapeutic effect could be obtained with a smaller dosage of cisplatin. The combination of AG1478 and cisplatin against OSCC definitely deserves additional in vivo and clinical studies.

Open Access This article is distributed under the terms of the Creative Commons Attribution Noncommercial License which permits any noncommercial use, distribution, and reproduction in any medium, provided the original author(s) and source are credited.

\section{References}

1. Salomon DS, Brandt R, Ciardiello F et al (1995) Epidermal growth factor-related peptides and their receptors in human malignancies. Crit Rev Oncol Hematol 19:183-232

2. Hiraishi Y, Wada T, Nakatani K et al (2006) Immunohistochemical expression of EGFR and p-EGFR in oral squamous cell carcinomas. Pathol Oncol Res 12:87-91

3. Huang SM, Harari PM (1999) Epidermal growth factor receptor inhibition in cancer therapy: Biology, rationale and preliminary clinical results. Invest New Drugs 17:259-269

4. Prenzel N, Fischer OM, Streit S et al (2001) The epidermal growth factor receptor family as a central element for cellular signal transduction and diversification. Endocr Relat Cancer 8:1131

5. Gibbs JB (2000) Anticancer drug targets: growth factors and growth factor signaling. J Clin Invest 105:9-13

6. Mendelsohn J (2001) The epidermal growth factor receptor as a target of cancer therapy. Endocr Relat Cancer 8:3-9

7. Herbst RS, Hong WK (2002) IMC-C225, anti-epidermal growth factor receptor monoclonal antibody for treatment of head and neck cancer. Semin Oncol 29:18-30

8. Fukuoka M, Yano S, Giaccone G et al (2003) Multi-institutional randomized phase II trial of gefitinib for previously treated patients with advanced non-small-cell lung cancer. J Clin Oncol 21:2237-2246

9. Mendelsohn J, Baselga J (2003) Status of epidermal growth factor receptor antagonists in the biology and treatment of cancer. J Clin Oncol 21:2787-2799

10. SaltzL B, Meropol NJ, Loehrer PJ et al (2004) Phase II trial of cetuximab in patients with refractory colorectal cancer that express the epidermal growth factor receptor. J Clin Oncol 22:1201-1208

11. Christen RD, Hom DK, Porter DC et al (1990) Epidermal growth factor regulates the in vitrosensitivity of human ovarian carcinoma cells to cisplatin. J Clin Invest 86:1632-1640

12. Aboud-Pirak E, Hurwitz E, Pirak ME et al (1988) Efficacy of antibodies to epidermal growth factor receptor against $\mathrm{KB}$ carcinoma in vitro and in nude mice. $\mathrm{J}$ Natl Cancer Inst 80:1605-1611

13. Dai Q, Ling YH, Lia M et al (2005) Enhanced sensitivity to the HER1/epidermal growth factor receptor tyrosine kinase inhibitor erlotinib hydrochloride in chemotherapy resistant tumor cell lines. Clin Cancer Res 11:1572-1578

14. Benhar M, Engelberg D, Levitzki A (2002) Cisplatin-induced activation of the EGF receptor. Oncogene 21:8723-8731

15. Bourhis J (2005) New approaches to enhance chemotherapy in SCCHN. Ann Oncol 16:20-24

16. Chan JK, Pham H, You XJ et al (2005) Suppression of ovarian cancer cell tumorigenicity and evasion of Cisplatin resistance using a truncated epidermal growth factor receptor in a rat model. Cancer Res 65:3243-3248

17. Nakamura M, Nakatani K, Uzawa K et al (2005) Establishment and characterization of a cisplatin-resistant oral squamous cell carcinoma cell line, H-1R. Oncol Rep 14:1281-1286

18. Nakatani K, Nakamura M, Uzawa K et al (2005) Establishment and gene analysis of a cisplatin-resistant cell line, Sa-3R, derived from oral squamous cell carcinoma. Oncol Rep 13:709-714

19. Downward J, Parker P, Waterfield MD (1984) Autophosphorylation sites on the epidermal growth factor receptor. Nature 311:483-485

20. Olayioye MA, Neve RM, Lane HA et al (2000) The ErbB signaling network: receptor heterodimerization in development and cancer. EMBO J 19:3159-3167 
21. Wang X, Martindale JL, Holbrook NJ (2000) Requirement for ERK activation in cisplatin-induced apoptosis. J Biol Chem 275:39435-39443

22. Benhar M, Dalyot I, Engelberg D et al (2001) Enhanced ROS production in oncogenically transformed cells potentiates c-Jun Nterminal kinase and p38 mitogen-activated protein kinase activation and sensitization to genotoxic stress. Mol Cell Biol 21:69136926

23. Deschesnes RG, Huot J, Valerie K et al (2001) Involvement of p38 in apoptosis-associated membrane blebbing and nuclear condensation. Mol Biol Cell 12:1569-1582
24. Chen Z, Zhang X, Li M et al (2004) Simultaneously targeting epidermal growth factor receptor tyrosine kinase and cyclooxygenase-2, an efficient approach to inhibition of squamous cell carcinoma of the head and neck. Clin Cancer Res 10:5930 5939

25. El-Marjou A, Delouvee A, Thiery JP et al (2000) Involvement of epidermal growth factor receptor in chemically induced mouse bladder tumor progression. Carcinogenesis 21:22112218

26. Wakeling AE (2002) Epidermal growth factor receptor tyrosine kinase inhibitors. Curr Opin Pharmacol 2:382-387 